\title{
The diabetes epidemic in Sri Lanka - a growing problem
}

\section{P Katulanda ${ }^{1,2}$, MHR Sheriff ${ }^{1}$ and DR Matthews ${ }^{2}$}

\begin{abstract}
Diabetes mellitus, which was once considered a disease of the developed world, has become a worldwide pandemic, with two thirds of the global diabetic population living in the developing countries. Local studies show a definite upward trend in the prevalence of diabetes mellitus. The earliest available study on a rural community in 1990 reported a prevalence of $2.5 \%$. The largest-ever study on the diabetes prevalence in Sri Lanka was published in 2005. It showed a prevalence of $14.2 \%$ among males and $13.5 \%$ among females.
\end{abstract}

The World Health Organisation and the International Diabetic Federation estimates and forecasts are much lower than the available local prevalence rates, and what may be predicted from the prevalence rates in South India. Further research is necessary to investigate the exact underlying mechanisms for the South Asian epidemic. Wider preventive programmes need to be urgently implemented to stem the tide.

\section{Introduction}

The world is facing a pandemic of diabetes mellitus, affecting both developed and developing countries [13]. By 2025, south east Asia is expected to be the region with the highest number of diabetic patients in the world [3]. Accurate figures of the prevalence of diabetes mellitus are needed for planning primary prevention programmes and secondary and tertiary care.

\section{Diabetes prevalence in Sri Lanka}

Several investigators have estimated the prevalence of diabetes mellitus in Sri Lanka over the last 15 years [4-9]. Most of the studies were on rural or suburban populations. The sample sizes varied between 220 and 6047. The criteria used to diagnose diabetes mellitus were different between studies. Fasting blood glucose was used in some studies, and the oral glucose tolerance test in others. The earlier studies have used the 1985 WHO criteria [10], and the newer studies used the 1997 American Diabetic Association (ADA) criteria [11] for diagnosis. The available studies show a definite upward trend in the prevalence of diabetes mellitus in Sri Lanka (Table 1).

A study done in 1990 [4] on a rural community using the oral glucose tolerance test and the 1985 WHO criteria for diagnosis reported a prevalence of $2.5 \%$. There were two studies published in 1994. One study [5] on a suburban community using the 1985 WHO criteria showed a prevalence of 5.02\% and the other study [6] on a mixed population using fasting blood glucose according to the 1985 WHO criteria indicated a prevalence of $5.87 \%$. These

${ }^{1}$ Department of Clinical Medicine, University of Colombo, Sri Lanka, ${ }^{2}$ Oxford Centre for Diabetes, Endocrinology and metabolism, Oxford, UK.

Correspondence: PK, e-mail: <Prasad.Katulanda@st-hughs.ox.ac.uk>. (Competing interests: none declared). Received 9 September 2005 and accepted 2 January 2006. 
two studies carried out in the same period by different groups show a similarity in prevalence. In a study published in 2002 [7] on a suburban population using fasting blood glucose according to the 1997 ADA criteria or established treatment for diabetes mellitus for diagnosis, a prevalence of $6.5 \%$ was reported. In the 2004 study [8] on a rural population similar to the population sampled in the 1990 study by the same authors, an increased prevalence of $8.5 \%$ was found. Results of a large study on the cardiovascular risk factors among adults between the ages of 30 and 65 carried out in four provinces in Sri Lanka was published in 2005 [9]. According to this study the prevalence rates are $14.2 \%$ for males and $13.5 \%$ for females.

\section{WHO and IDF estimations and projections}

According to the 1998 WHO estimations and projections on diabetes prevalence of its member countries for the years 1995, 2000 and 2025, the estimated and projected figures for Sri Lanka were 2.5\%, 2.6\% and 3.5\%, respectively [2]. These extrapolations had been based on a study done in Thailand and were markedly lower than the prevalence rates available from the local studies. In 2004, WHO published revised estimates for the diabetes prevalence of its member countries.

These estimates are 5.4\% for the year 2000 [12] and a projected number of 1537000 cases for the year 2030 [13] for Sri Lanka. The calculated prevalence based on the above WHO figure for the year 2030 and the population forecasts of the United Nations [14] is 7\%. The International Diabetic Federation (IDF) prevalence estimates are $2.1 \%$ for year 2003 and $2.7 \%$ for the year 2025 [3].

\section{Regional data}

Historically, it is believed that the majority of Sri Lankans have descended from India. The body build and lifestyle of Sri Lankans show marked similarities to those of South Indians. Hence, it is important to compare the local prevalence figures with those of South India. Ramachandran and colleagues [14-16] analysed the studies done in urban and rural South India from 1989 to 2003 and reported on the temporal trends in diabetes prevalence. In urban South India three studies done in 1989, 1995 and 2000 showed prevalence rates of $8.3 \%$, $11.6 \%$ and $13.9 \%$, respectively, for adults. In a similar analysis on the rural data, diabetes prevalence was shown to increase from $2.2 \%$ in 1989 to $6.36 \%$ in 2003 . These figures are shown in relation to the Sri Lankan prevalence data in Table 2.

When compared with Indian urban data, Sri Lankan data show lower prevalence rates for suburban and rural populations. However, the Indian rural prevalence rates are slightly lower than the Sri Lankan rural rates in the corresponding periods. The recently published prevalence rates in Sri Lanka for the entire country closely resemble the Indian prevalence rates for the urban population published 5 years ago. Since the larger proportion of Sri Lankan population still lives in rural areas there is a possibility for the overall Sri Lankan diabetes prevalence to be higher than that of India. Despite this, IDF estimates [17] and projections are much lower for Sri Lanka compared to those of India. IDF and WHO estimates and projections for the two countries are shown in Table 3.

Table 1. Temporal changes in the prevalence of diabetes mellitus in Sri Lanka.

Data from cross sectional studies (References 4-9)

\begin{tabular}{|c|c|c|c|c|c|c|}
\hline Year & 1993 & $1994 a$ & $1994 b$ & 2000 & 2004 & 2005 \\
\hline Author & $\begin{array}{l}\text { Illangasekera } \\
\text { et al. [4] }\end{array}$ & $\begin{array}{l}\text { Fernando } \\
\text { et al. [5] }\end{array}$ & $\begin{array}{l}\text { Mendis } \\
\text { et al. [6] }\end{array}$ & $\begin{array}{l}\text { Malavige } \\
\text { et al. [7] }\end{array}$ & $\begin{array}{l}\text { Illangasekera } \\
\text { et al. [8] }\end{array}$ & $\begin{array}{l}\text { Wijewardena } \\
\text { et al. [9] }\end{array}$ \\
\hline Sample size & 220 & 633 & 975 males & 1303 & 220 & 6047 \\
\hline $\begin{array}{l}\text { Age } \\
\text { distribution }\end{array}$ & Above 18 years & 30-64 years & $35-59$ years & 30-64 years & Above 18 years & $30-65$ years \\
\hline Prevalence & $2.5 \%$ & $5.02 \%$ & $5.8 \%$ & $6.5 \%$ & $8.5 \%$ & $\begin{array}{l}\text { Males } 14.2 \% \\
\text { Females } 13.5 \%\end{array}$ \\
\hline
\end{tabular}

Table 2. The measured prevalence rates from Sri Lankan and Indian studies

\begin{tabular}{|c|c|c|c|c|c|c|}
\hline Year & 1989 & 1993 & 1994-1995 & 2000 & $2003 \& 2004$ & 2005 \\
\hline $\begin{array}{l}\text { Sri Lankan } \\
\text { prevalence }(\%)\end{array}$ & & $\begin{array}{l}2.5[4] \\
\text { (Rural) }\end{array}$ & $\begin{array}{l}5.02[5] \text { Males } \\
5.8[6] \text { (Suburban) }\end{array}$ & $\begin{array}{l}6.5[7] \\
\text { (Suburban) }\end{array}$ & $\begin{array}{l}8.5[8] \\
\text { (Rural) }\end{array}$ & $\begin{array}{l}\text { Males } 13.5 \\
\text { Females } 14.2 \text { [9] } \\
\text { (Island wide) }\end{array}$ \\
\hline Indian rural (\%) & $2.2[16]$ & & & & 6.36 [16] & \\
\hline Indian urban (\%) & & 8.3 [15] & 11.6 [15] & $13.90[15]$ & 8.6 [15] & \\
\hline
\end{tabular}


Table 3. WHO and IDF estimates and projections of diabetes mellitus for Sri Lanka and India

\begin{tabular}{|c|c|c|c|}
\hline & 2000 & 2003 & 2025 \\
\hline $\begin{array}{l}\text { WHO estimates- } \\
\text { Sri Lankan }\end{array}$ & $5.4 \%[12]^{*}$ & & 67 per $1000[13] \dagger$ \\
\hline $\begin{array}{l}\text { WHO estimates- } \\
\text { Indian }\end{array}$ & $5.5 \%[12]^{*}$ & & 60 per $1000[13] \dagger$ \\
\hline $\begin{array}{l}\text { IDF estimates- } \\
\text { Sri Lankan }\end{array}$ & & $2.1 \%[3]^{*}$ & $2.7 \%[3]^{*}$ \\
\hline $\begin{array}{l}\text { IDF estimates- } \\
\text { Indian }\end{array}$ & & $5.9 \%[3]^{*}$ & $8.1 \%[3]^{*}$ \\
\hline
\end{tabular}

*prevalence among adults over 20 years, 'prevalence in the total population

\section{Conclusion}

Available diabetes prevalence data in Sri Lanka show a definite upward trend. According to the data from recently published studies, Sri Lanka is among the countries with the highest diabetes prevalence rates in the world. According to estimates, there should be 2.8 million adults with diabetes mellitus in Sri Lanka at present and a significant proportion of this may yet be undiagnosed. If we were to provide at least the basic care for these subjects, the existing health care facilities in the island would be simply overwhelmed. The revision of the WHO estimates according to available local data instead of extrapolations based on other populations is a significant advance. However, IDF estimates are still much lower than those that could be predicted from available local data and data from the neighbouring South India. There is a large discrepancy between IDF and WHO estimates. Most of the reported studies have not looked at the problem among young adults and the elderly due to practical difficulties.

The WHO and IDF estimates on the prevalence of diabetes mellitus and projections for the future for Sri Lanka need to be revised, based on the data from recent large epidemiological studies. Although rapid changes in lifestyle are believed to be important underlying causes, further research should be encouraged to investigate the cause(s) of the current epidemic in Sri Lanka and in South Asia, with a view to planning effective preventive measures. Preventive programmes need to be planned and implemented urgently at the national level to stem the tide.

\section{References}

1. Wild, Roglic G, Green A, Sicree R, King H. Global prevalence of diabetes: estimates for the year 2000 and projections for 2030. Diabetes Care 2004; 27: 1047-53.

2. King H, Aubert RE, Herman WH. Global burden of diabetes, 1995-2025: prevalence, numerical estimates, and projections. Diabetes Care 1998; 21: 1414-31.

3. International Diabetes Federation. World Diabetes Foundation. Diabetes Atlas: executive summary. 2nd ed. Brussels: IDF Executive Office, 2003; 7-11.
4. Illangasekera U, Nugegoda DB, Perera LS. Prevalence of diabetes mellitus and impaired glucose tolerance in a rural Sri Lankan community. Ceylon Medical Journal 1993; 38: 123-6.

5. Fernando DJ, Siribaddana S, de Silva D. Impaired glucose tolerance and diabetes mellitus in a suburban Sri Lankan community. Postgraduate Medical Journal 1994; 70: 347-9.

6. Mendis S, Ekanayake EM. Prevalence of coronary heart disease and cardiovascular risk factors in middle aged males in a defined population in central Sri Lanka. International Journal of Cardiology 1994; 46: 135-42.

7. Malavige GN, de Alwin NM, Weerasooriya N, Fernando DJ, Siribaddana SH. Increasing diabetes and vascular risk factors in a sub-urban Sri Lankan population. Diabetes Research Clinical Practice 2002; 57: 143-5.

8. Illangasekera U, Rambodagalla S, Tennakoon S. Temporal trends in the prevalence of diabetes mellitus in a rural community in Sri Lanka. Journal of Royal society of Health 2004; 124: 92-4.

9. Wijewardena K, Mohideen MR, Mendis S, Fernando DS, Kulathilaka T, et al. Prevalence of hypertension, diabetes and obesity: baseline findings of a population based survey in four provinces in Sri Lanka. Ceylon Medical Journal 2005; 50: 62-70.

10. World Health Organization. Diabetes Mellitus: Report of a WHO Study Group. Geneva: WHO, 1985. Technical Report Series 727.

11. The Expert Committee on the Diagnosis and Classification of Diabetes Mellitus. Report of the Expert Committee on the diagnosis and classification of diabetes mellitus. Diabetes Care 1997; 20: 1183-97.

12. Mackay Judith GAM, Mendis S, Greenland K. The Atlas of Heart Disease and Stroke. Geneva: World Health Organisation, 2004: 90-1.

13. World Health Organisation. Country and Regional Data. Diabetes Programme 2004. Geneva: WHO. Available at: http://www.who.int/diabetes/facts/world_figures/eu/ index.5html. Accessed on 27 April 2005.

14. UN-Habitat. United Nations Human Settlement Programme. Global Statistics 2003. Available at http// www.unhabitat.org/programmes/guo/data_hsdb4.asp. Accessed April 27, 2005.

15. Ramachandran A, Snehalatha C, Vijay V. Temporal changes in prevalence of type 2 diabetes and impaired glucose tolerance in urban southern India. Diabetes Research Clinical Practice 2002; 58: 55-60.

16. Ramchandran A, Snehalatha C, Baskar AD, Mary S, Kumar CK, Selvam S, et al. Temporal changes in prevalence of diabetes and impaired glucose tolerance associated with lifestyle transition occurring in the rural population in India. Diabetologia 2004; 47: 860-5.

17. International Diabetes Federation. World Diabetes Foundation. Diabetes Atlas: 2nd ed. Brussels: IDF Executive Office, 2003; 60-61. 